\title{
HPLC, UV Spectrum Analysis of Polyherbal Formulation and DNA Damage in Hepatoprotective $\mathrm{CCl}_{4}$ Induced Albino Rats
}

\author{
A Dhinek ${ }^{1}$, C Sowmia ${ }^{2}$ \\ Department of Biochemistry, Dr.N.G.P College of Arts and Science, Coimbatore - 641048, Tamilnadu, India
}

\begin{abstract}
The objective of this study was to investigate the hepatoprotective activity of ethonolic extract of polyherbalformulation (Solanumxanthocarpum, Glycyrrhizaglabra, Ricinuscommunis, and Phyllanthusniruri leaves) against carbon tetrachloride $\left(\mathrm{CCl}_{4}\right)$ induced hepatotoxicity. The plants were dried in shade then powdered, extracted with ethanol. Preliminary phytochemical tests were done with the ethanolic extract showed presence of mostly all the compounds. The hepatoprotective activity of the ethonolic extract was assessed in $\mathrm{CCl}_{4}$ induced hepatotoxic albino rats. HPLC and $U V$ spectrum analysis revealed to identify and to quantify each component.The present study that exhibit free radical scavenging properties. DNA damage in liver was also evaluated using Comet assay. The DNA damages and the length are tested, Progression of liver damage induced by $\mathrm{CCl}_{4}$ in albino rats can be intervened using the polyherbal extract and these effects are comparable to those of silymarin, polyherbal treatments effectively restored these measurements closer to their normal levels.
\end{abstract}

Keywords: Hepatoprotection, Hepatotoxicity, $\mathrm{CCl}_{4}$, Sylimerin, Polyherbal drugs

\section{Introduction}

The liver is an organ responsible for the metabolism, bile secretion, elimination of many substances, blood detoxifications, synthesizes, and regulation of essential hormones. The principal causative factors for the liver diseases in developed countries are excessive consumption of alcohol, viral-induced chronic liver diseases environmental toxins, parasitic disease, hepatitis $\mathrm{B}$ and $\mathrm{C}$ viruses, and hepatotoxic drugs (certain antibiotics, chemotherapeutic agents, high doses of paracetamol, carbon tetrachloride $\left(\mathrm{CCl}_{4}\right)$, thioacetamide (TAA), etc. Chronic liver cirrhosis, drug induced liver injury accounting the ninth leading cause of death in western and developing countries. In the absence of reliable hepatoprotective drugs in modern medicine, a large number of herbal preparations have become increasingly popular for the treatment of liver disorders [1]. Toxins and drugs are among the basic etiopathogenetic agents of acute liver failure in Western countries [2]. Nevertheless, chemical toxins (including acetaminophen, carbon tetrachloride, galactosamine and thioacetamide) are often used as the model substances causing experimental hepatocyte injury in both in vivo and in vitro conditions [3]. An antioxidant may serve as a hepatoprotective agent. Therefore, the antioxidant mechanism is a major defense system, which converts active oxygen molecules into nontoxic compounds and finally revert cellular damage [4]. In the absence of reliable hepatoprotective drugs in modern medicine, a large number of herbal preparations have become increasingly popular for the treatment of liver disorders [5]. A number of herbals show promising activity, including silymarin for liver cirrhosis, Phyllantusamarus in chronic hepatitis B, glycyrrhizin to treat chronic viral hepatitis, and some herbal combinations from China and Japan that have been scientifically proven for treatment of liver diseases [6]. Silymarin, a flavonolignan from "milk thistle" Silybummarianum, is widely used for hepatoprotection. Silymarin showed good protection in different toxic models of induced liver cirrhosis experiments by using laboratory animals [7]. Since only few number of herbs have been studied so far have just opened a wide horizon, it is worth to screen other plant extracts and natural compounds in appropriate model systems and to identify further compounds combining antioxidant properties with other effectors functions. Such studies may lead to new drugs particularly appropriate and specifically designed to block liver cirrhosis at early steps of disease. This study was carried out to assess the in vivo hepatoprotective and antioxidant activities of herbal plants like Solanumxanthocarpum, Fossil Coleopter, Phyllanthus emblica, Ricinus communis against wistar rats with liver damage induced by carbon tetrachloride $\left(\mathrm{CCl}_{4}\right)$ in rats to prove scientifically the traditional use of four plants against liver disorders as well as, to determine their in vitro antioxidant and immunomodulatory properties. The comet assay is a simple and sensitive methodology for measuring strand breaks of DNA in single cells. Cells are anchored in a layer of agarose on a microscope slide and membrane is lysed and removed with detergent and high salt solution leaving a nucleoid. The DNA strand breaks, if present, will be relaxed in the supercoiled loops of DNA.

\section{Materials and Methods}

2.1 Collection and preparation of the plant powder, extraction

Plant samples were collected in Sulur, Coimbatore. Samples were collected, milled and Formulation was made by taking equal proportion of each powdered plant samples. Each of the plant material was taken in 1:1:1:1 ratio and soaked with $50 \%$ ethanol for $48 \mathrm{hrs}$. Then, the extract was evaporated to dryness and the final dry extract was stored in dark at $-20^{\circ} \mathrm{C}$ until used for the experiments. The percentage yield of extract was $17.7 \%(\mathrm{w} / \mathrm{w})$ of the initial raw material. 


\section{International Journal of Science and Research (IJSR) \\ ISSN (Online): 2319-7064 \\ Index Copernicus Value (2015): 78.96 Impact Factor (2015): 6.391}

\subsection{Selection and Grouping of Animals}

Animals male Wistar rats weighing 200- $230 \mathrm{~g}$ were used in the study. The animals were maintained in an air conditioned animal house at a temperature of $22 \pm 2{ }^{\circ} \mathrm{C}$, relative humidity of $57 \pm 2 \%$ and photocycle of $12: 12 \mathrm{~h}$ light and dark. The animals were provided with standardized pelleted feed and drinking water ad libitum. All the experimental procedures were carried out in accordance with the guidelines of the Institutional Animal Ethics Committee. The animals were observed daily for any signs of toxicity. Body weight was recorded at regular intervals throughout the experimental period.

\subsection{Acute Oral Toxicity Study}

The acute toxicity study was carried on albino mice as per the guidelines No: 423 given by the Organization for Economic Co-operations and Development, Paris [OECD 423, 2001). Three Albino mice were fasted over night and the test sample PHE was given orally at a starting dose of 5 $\mathrm{mg} / \mathrm{kg} \mathrm{b}$. wt. Animals were observed for a period of $2 \mathrm{~h}$, then occasionally for $4 \mathrm{~h}$ for severity of any toxic signs and mortality. Since no mortality was observed, same dose was repeated with another group of animals. The procedure was repeated for doses of 50, 300 and $2000 \mathrm{mg} / \mathrm{kg}$ in separate group of animals. From the maximum dose of $2000 \mathrm{mg} / \mathrm{kg}$, $1 / 10$ th and $1 / 5$ th of the values were taken as treatment dose for further studies [8]. Behaviors as well as other toxic symptoms if any were observed for 24,48 and $72 \mathrm{~h}$. The animals were kept under observation up to $14 \mathrm{~d}$ after drug administration to find out delayed mortality if any.

\subsection{UV Analysis}

Ultraviolet light:wavelengths between 190 and 400nm, Visible light:wavelengths between 400 and $800 \mathrm{~nm}$. Ultraviolet/visible spectroscopy involves the absorption of ultraviolet light by a molecule causing the formation of an electron from a ground electronic state to an excited electronic, Setting the zero with ethanol in different $\mathrm{nm}$ setting. it is upstream, downstream two procees. Loding the sample. reading the optical density for absorption.

\subsection{HPLC Analysis}

$20 \mathrm{~g}$ of sample was weighed, and then dissolved in $20 \mathrm{ml}$ HPLC methanol, the sample was shaken and agitated in ultrasonic bath for 10 minutes, then was further concentrated by evaporating the solvent with a stream of liquid N2 until reach nearly $0.5 \mathrm{ml}$, and then add some mobile phase to reach $1 \mathrm{ml}$. Then $20 \mu \mathrm{l}$ was injected on HPLC column. The concentration for each compound was quantitatively determined by comparing the peak area of the standard with that of the samples. The phenolic compounds separated on fast liquid chromatographic under optimum condition. Column details: $3 \mu \mathrm{m}$ particle size $(50 \times 4.6 \mathrm{~mm}$ I.D) $\mathrm{C}-18$ column, mobile phase: phosphate buffer $0.01 \%$ : acetic acid: methanol:water (0.01:40:60). Flow rate $1.4 \mathrm{ml} / \mathrm{min}$, detection UV set at $264 \mathrm{~nm}$.

\subsection{Comet Assay}

The comet assay is a simple and sensitive methodology for measuring strand breaks of DNA in single cells. Cells are anchored in a layer of agarose on a microscope slide and membrane is lysed and removed with detergent and high salt solution leaving a nucleoid. The DNA strand breaks, if present, will be relaxed in the supercoiled loops of DNA. A small electrical current is applied through the gel, the DNA loops are then pulled towards the anode forming a comet like structure. Comets can be visualized under fluorescent microscopy stained by ethidium bromide or propidium iodide etc. The amount of DNA in the tail, relative to the head, is proportional to the amount of strand breaks. The comet assay can be applied to nearly all eukaryotic cells with lymphocytes as the most commonly used type of cell in human studies. Various modification of comet assay has been developed to achieve various objectives [9].

\section{Result \& Discussion}

\subsection{HPLC}

High-performance liquid chromatography is a technique in analytical chemistry used to separate the components in a mixture, to identify each component, and to quantify each component.

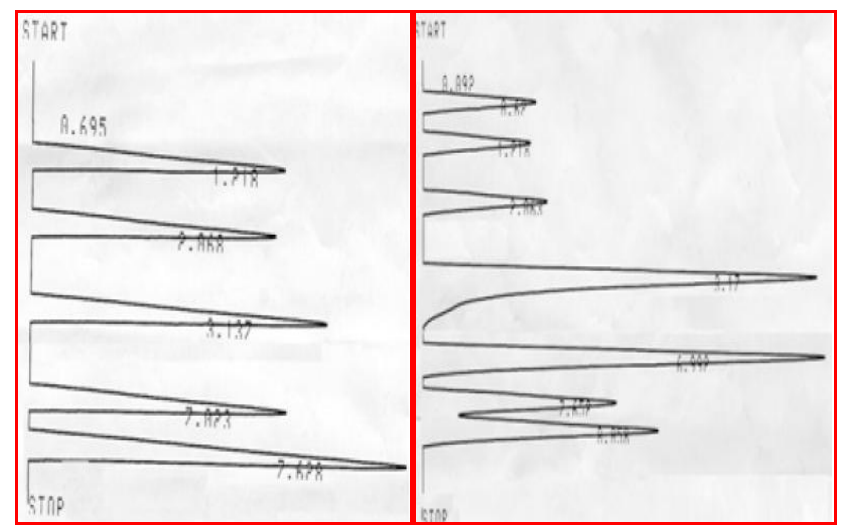

Figure 1: HPLC chromatogram of standard \& test sample

The extract of the polyherbal formulation was subjected to HPLC and the obtained records were superimposed on the retention time values of the extract. Standard phytocompounds used were Tannin acid, Gallic acid ,caffeic acid, chlorogenic and cinnamic acid, HPLC chromatogram of standard reveals the chromatogram with retention time, area of the standards, Chromatogram of test sample shows the chromatogram of extract of polyherbal, which was compared with the standards and found to contain Tannic acid,Gallicacid,Caffic acid, chlorogenic acid and cinnamic acid. It can be compared with the previous available reports. Caffeic acid has the highst concentration followed by chlorogenic acid $(28.04,24.39) \mu \mathrm{g} / \mathrm{ml}$ respectively Chromatogram of test sample.The spectrum of these compounds possescs wide range of medicinal value. Caffeic acid and chlorogenic acid anatural phenolic compound are normally abundant in medicinal plants and possesses multiple biological effect such as anti -bacterial, antioxidant and antidiabetic effect [10]. 


\section{International Journal of Science and Research (IJSR) \\ ISSN (Online): 2319-7064}

Index Copernicus Value (2015): 78.96 | Impact Factor (2015): 6.391

\subsection{UV-Visible spectrum}

UV spectra was monitored over 24 hours with periodic sampling of the reaction mixture using UV-visible spectrum (double beam, Elico) at different time intervals within the range of $200-800 \mathrm{~nm}$.

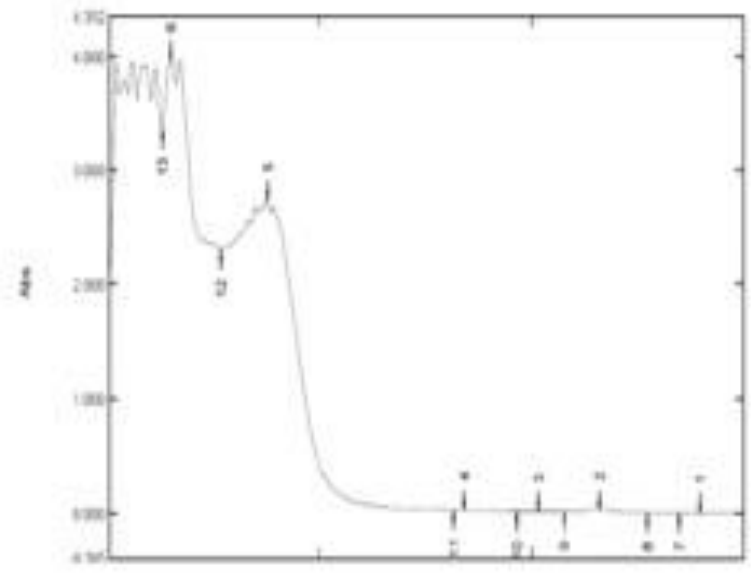

Figure 2: UV spectrum of polyherbal extract

\subsection{Comet Assay}

The single-cell gel electrophoresis (comet assay) allows detection of DNA fragmentation in single cells, and was initially used for DNA damage estimation. Figures showed the effect of carbon tetrachloride on mean DNA damage, comet length, tail length and mean comet tail length. The damage was expressed as percent DNA migration in the tail and 20-25 nuclei were counted in each slide. In all CCl4 treated groups $(1.5 \mathrm{ml} / \mathrm{kg})$, the tail lengths were significantly increased in liver $(42.6 \mu \mathrm{m})$ and kidney $(74.6 \mu \mathrm{m})$. DNA damage was elevated the tail length and movement was significant high. Therapy with the active principle as tannic acid controlled DNA damage significantly as evident from the decrement of mean tail length when compared to control treated group. This procedure has been widely used for genotoxicity studies and for monitoring the exposure to DNA damaging agents in human populations. We assessed the extent of damage, which entailed measurement of comet length, tail movement, tail length and tail DNA (\%) damage. Our data suggests that toxicant treatment was associated with oxidative stress induced DNA damage in liver and kidney. Therapy with PHE extracts clearly prevented the densitometric and geometric parameters of the comets as determined using image analysis software. Similar results were proved by Mittal in 2012 in PolygonumBistorta.
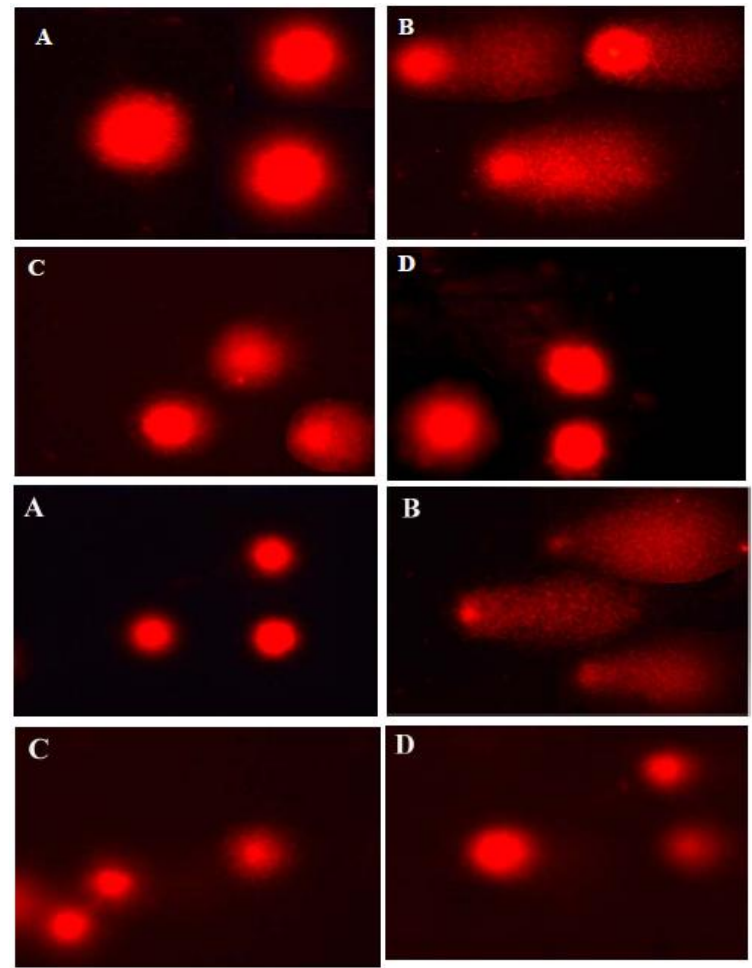

\section{Conclusion}

It was concluded from the results that the plant extracts were found to have prominent phytochemicals. The polyherbal formulation prepared from the ethanolic extracts of all the selected plants was observed to have various bioactive compounds identified and quantify each component through UV Visible spectrophotometer and HPLC analysis. Chromatogram of test sample shows the chromatogram of extract of polyherbal, which was compared with the standards and found to contain Tannic acid,Gallicacid,Caffic acid, chlorogenic acid and cinnamic acid.The spectrum of these compounds possescs wide range of medicinal value. The result of the acute toxicity test suggests that the polyherbal extract of the plant was non-toxic to albino rats. It was evident from the present study that the formulation was effective. This formulation can be further investigated for its various pharmacological properties. The hepatic damage was induced by $\mathrm{CCl} 4$, the effect of $\mathrm{CCl} 4$ on mean DNA damage, comet length, tail length and mean comet tail length changed. The damage was expressed as percent DNA migration in the tail and 20-25 nuclei were counted in each slide, after the induction of polyherbal extract it comes to the normal condition.

\section{References}

[1] M.A.Alshawsh, M.A. Abdulla, S.Ismail, Z.A. Amin, "Hepatoprotective effects of orthosiphonstamineus extract on thioacetamide-induced liver cirrhosis in rats", Evidence-Based Complementary and Alternative Medicine, pp. 6, 2011.

[2] Akram Eidi, Pejman Mortazavi, Maryam Bazargan and Jalal Zaringhalam, "Hepatoprotective activity of cinnamon ethanolic extract against ccl4-induced liver injury in rats, excli journal, Vol 11, pp. 495-507, 2012. 
[3] E. Gabele, M. Fron, G.E. Aeteel, T. Uesugi, C. Hellerbrand and J. Scholmerich, "TNFalpha is required for cholestasis-induced liver fibrosis in the mouse", BiochemBiophys Res Commun; Vol 378, pp. 348-53, 2009.

[4] T. Chatterjee, Medicinal plants with hepatoprotective properties. Herbal Options. $3^{\text {rd }}$ Edn. Calcutta Books and Allied (P) Ltd., pp, 135, 2000.

[5] F. Stickel, D.Schuppan, "Herbal medicine in the treatment of liver diseases", Digestive and Liver Disease, 39(4), pp. 293-304, 2007.

[6] A. Ghosh, T. Ghosh, S. Jain, "Silymarin-A review on the pharmacodynamics and bioavailability enhancement approaches", Journal of Pharmaceutical Science and Technology, 2(10), pp. 348-355, 2010.

[7] M.O.M. Tanira, A.M. Ageel, M.Tariq, A.Mobsin and A.H. Shah, "Evaluation of some pharmacological, microbiological and physical properties of Zizyphusspinachristi”. International Journal of Crude Drug Research, 26, pp. 56- 60, 1988.

[8] Muhammad Ahmed, M.A. Aisha Azmat, Azeem, Naviad-ul- Zafar and S.I.Ahmad, "Hepatoprotective effect of Barrisal (herbal drug) on carbon tetrachloride induced hepatic damage in rats", African Journal of Pharmacy and Pharmacology, Vol. 7(15), pp. 776-784, 2013.

[9] M. Nirmala, K. Girija, K. Lakshman, and T.Divya, "Hepatoprotective activity of Musa paradisiacaon experimental animal models". Asian Pacific Journal of Tropical Biomedicine, Vol 10, pp.11-15, 2012.

[10]A. Dhawan, D.Anderson, S. De Pascual-Teresa, C. Santos Buelga, M.N. Clifford and C. Loannides, "Protective effect of epigallocatechin gallate against nnitrosodiethylamine (ndea) induced toxicity in rats", 2002. 